Supporting Information For:

\title{
Peptide-Induced Lipid Flip-Flop in Asymmetric Liposomes: Measured by Small Angle Neutron Scattering
}

Michael H.L. Nguyen, Mitchell DiPasquale, Brett W. Rickeard, Milka Doktorova, Frederick A. Heberle, Haden L. Scott, Francisco N. Barrera, Graham Taylor, Charles P. Collier, Christopher B. Stanley, John Katsaras, and Drew Marquardt 

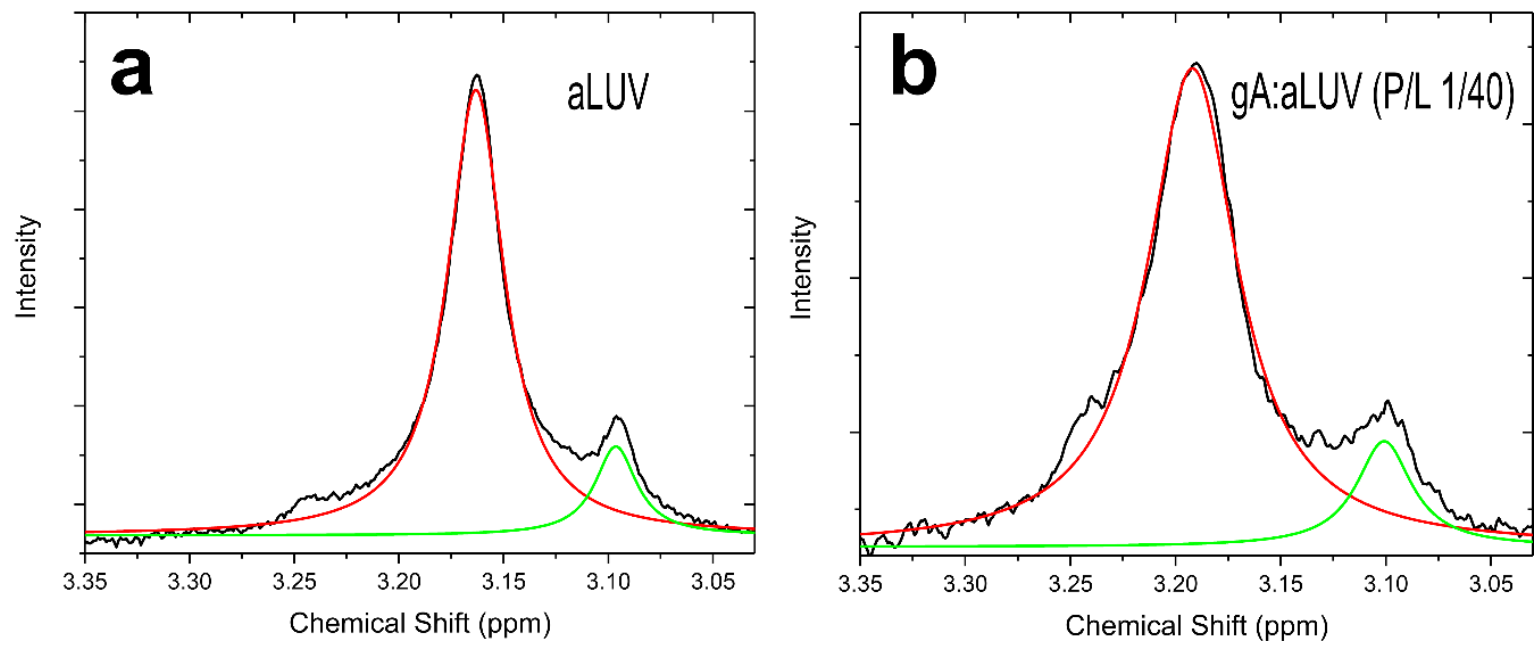

Figure S1. ${ }^{1} \mathrm{H}$ NMR spectra of dH-POPC ${ }^{\text {in }} / \mathrm{dC}-\mathrm{DMPC}^{\text {out }}$ aLUVs in $\mathrm{D}_{2} \mathrm{O}$ (a) and with gramicidin (gA) at a gA-to-lipid ratio of 1/40 (b). Shown are the two choline resonance peaks from the nondeuterated PC headgroups in the presence of $20 \mathrm{mM} \mathrm{Pr}^{3+}$ shift reagent. Outer leaflet PC lipids are represented by the red peaks that are shifted downfield as a result of the headgroups interacting with $\mathrm{Pr}^{3+}$. Because $\mathrm{Pr}^{3+}$ does not permeate the vesicle lumen during NMR measurement, green peaks correspond to $\mathrm{PC}$ headgroups located in the inner leaflet.

Table 1. Summary table of the measured lipid distributions of aLUVs with and without gA.

\begin{tabular}{|c|c|c|c|c|}
\hline \multicolumn{5}{|c|}{ aLUV } \\
\hline Component & $\boldsymbol{f}^{\text {out }}$ & $\boldsymbol{\chi}^{\text {total }}$ & $\boldsymbol{\chi}^{\text {inn }}$ & $\boldsymbol{\chi}^{\text {out }}$ \\
\hline dC-DMPC & $0.87^{\text {a }}$ & $0.38^{\mathrm{b}}$ & 0.10 & 0.66 \\
\hline dH-POPC & - & $0.62^{\mathrm{b}}$ & 0.90 & 0.34 \\
\hline Total & - & 1 & 1 & 1 \\
\hline \multicolumn{5}{|c|}{ aLUV $+\mathrm{gA}(\mathrm{L} / \mathrm{P}=40 / 1)$} \\
\hline $\mathrm{dC}-\mathrm{DMPC}$ & $0.88^{\mathrm{a}}$ & $0.42^{\mathrm{b}}$ & 0.10 & 0.74 \\
\hline $\mathrm{dH}-P O P C$ & - & $0.58^{\mathrm{b}}$ & 0.90 & 0.26 \\
\hline Total & - & 1 & 1 & 1 \\
\hline
\end{tabular}

Values obtained from ${ }^{1} \mathrm{H} \mathrm{NMR}^{\mathrm{a}}$ and gas chromatography/mass spectrometry $(\mathrm{GC} / \mathrm{MS})^{\mathrm{b}}$. $f^{\text {out }}$ represents the fraction of dC-DMPC in the bilayer outer leaflet. From left to right, $\chi$ represents the mol fraction of lipids in the total vesicle, inner leaflet and outer leaflet. 
Determination of Asymmetric Bilayer Structure

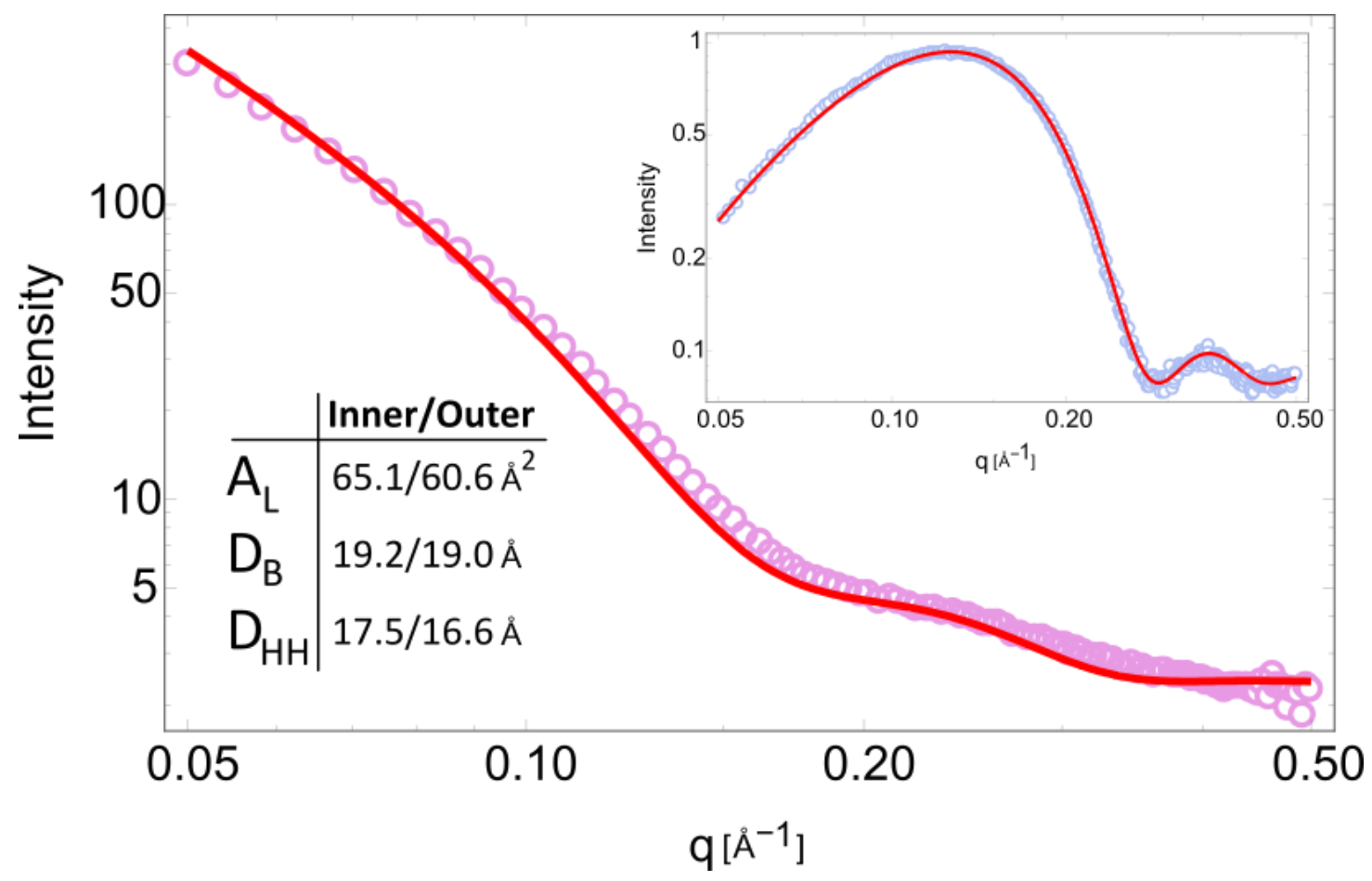

Figure S2. Small angle neutron scattering (SANS) data of aLUVs composed of dH-POPC ${ }^{\mathrm{inn} / \mathrm{dC}-}$ DMPC $^{\text {out }}$. Inset: Small angle X-ray scattering curve (SAXS) of the same aLUV control. Bold continuous lines are fits from a joint analysis of SANS and SAXS curves based on the exact distribution of dH-POPC and dC-DMPC in the bilayer determined from NMR and GC/MS ${ }^{6}$. The fits resulted in the determination of area per lipid $\left(A_{L}\right)$, bilayer thickness $\left(D_{B}\right)$ and headgroupheadgroup thickness $\left(\mathrm{D}_{\mathrm{HH}}\right)$ in the individual bilayer leaflets. Percent error is estimated to be $<3 \%$ according to Eicher and colleagues ${ }^{1}$. 
Confirmation of Peptide Incorporation into Asymmetric Vesicles
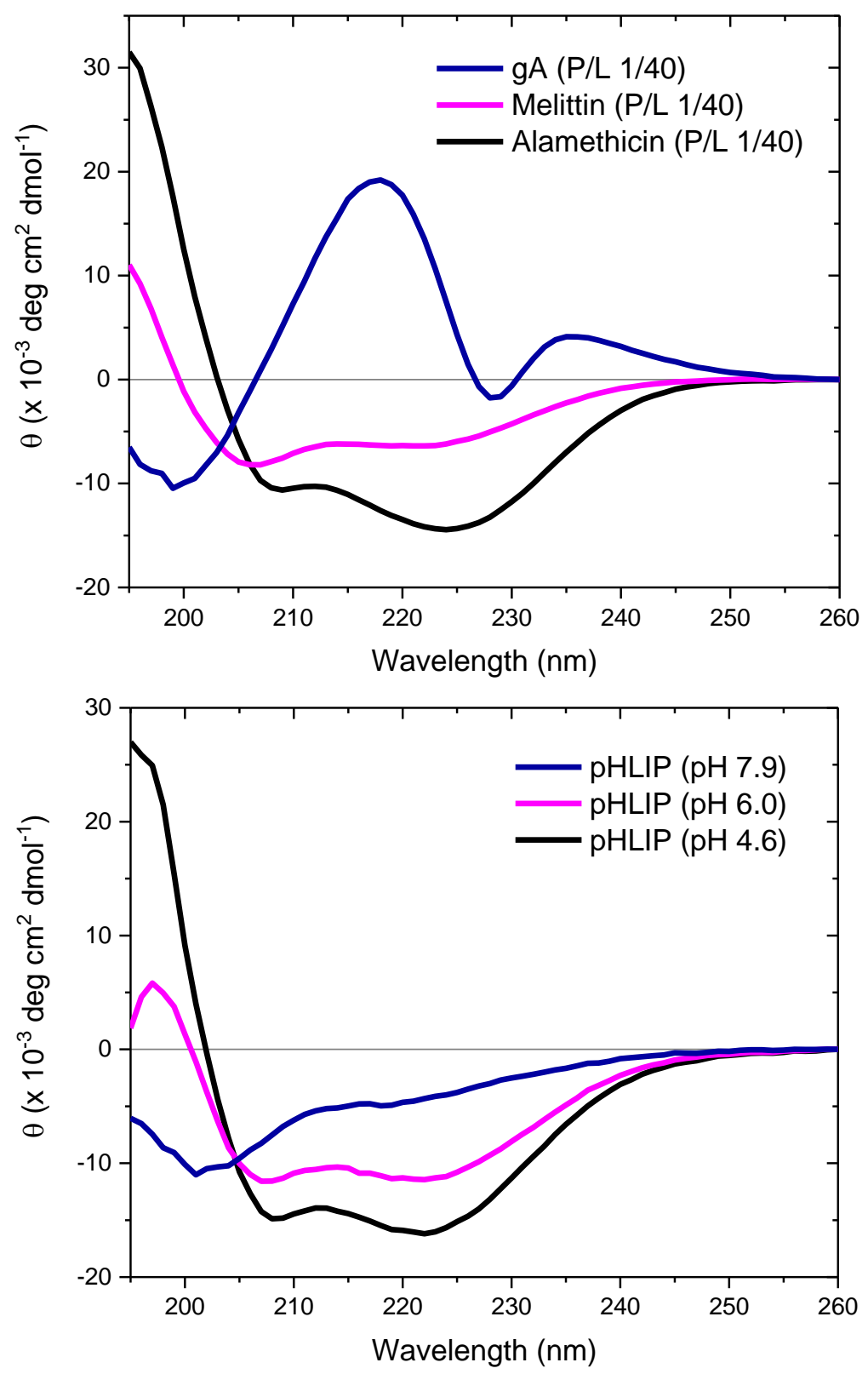

Figure S3. Circular dichroism spectra obtained from aLUV samples with different peptides. Top panel: gramicidin spectrum indicative of the peptide adopting a dimer ${ }^{2}$, while the spectra from melittin and alamethicin are indicative of alpha-helical conformations ${ }^{3-4}$. Bottom panel: at $\mathrm{pH} 7.9$, pHLIP is in a mostly unstructured state; at $\mathrm{pH} 6.0$ a portion of pHLIP monomers are in the inserted alpha helical state ${ }^{5-6}$; at $\mathrm{pH} 4.6$ a much greater portion of $\mathrm{pHLIP}$ is alpha helical ${ }^{5-6}$. All pHLIPaLUV experiments were done at a $\mathrm{P} / \mathrm{L}$ ratio of $1 / 150$. 
Deuterated Methanol does not Initiate Rapid and Complete Lipid Bilayer Scrambling

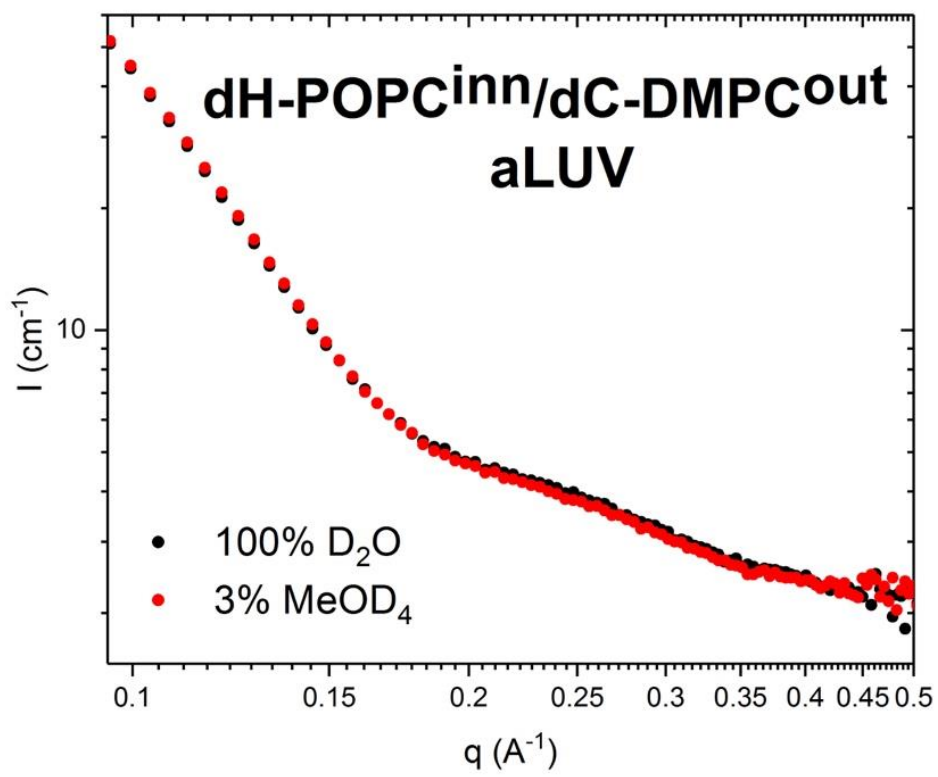

Figure S4. SANS curves of dH-POPC ${ }^{\text {in }} / \mathrm{dC}$-DMPC ${ }^{\text {out }}$ aLUVs in the presence of $100 \% \mathrm{D}_{2} \mathrm{O}$ (black circles) and $3 \%(\mathrm{v} / \mathrm{v})$ of deuterated methanol (d-methanol) in $\mathrm{D}_{2} \mathrm{O}$. The inclusion of d-methanol does not result in a drastic change in scattering pattern, meaning no change in lipid organization occurred. Thus, d-methanol is not responsible for the immediate and rapid lipid scrambling observed in this study; instead, the peptides are the major actors. 


\section{References}

[1] Eicher, B., Heberle, F. A., Marquardt, D., Rechberger, G. N., Katsaras, J., \& Pabst, G. (2017). Joint small-angle X-ray and neutron scattering data analysis of asymmetric lipid vesicles. Journal of Applied Crystallography, 50, 419-429. https://doi.org/10.1107/S1600576717000656

[2] Galbraith, T.P. and B.A. Wallace, Phospholipid chain length alters the equilibrium between pore and channel forms of gramicidin. Faraday Discuss, 1998(111): p. 159-64; discussion 22546.

[3] De Jongh, H. H. J., Goormaghtigh, E., Killian, J. A., De Jongh, H. H. J., Goormaghtigh, E.,Killian, J. A., ... Goormaghtigh, E. (1994). Analysis of Circular Dichroism Spectra of Oriented Protein-Lipid Complexes: Toward a General Application. Biochemistry, 33(48), 14521-14528. https://doi.org/10.1021/bi00252a019.

[4] Wu, Y., Huang, H. W., \& Olah, G. A. (1990). Method of oriented circular dichroism. Biophysical Journal, 57(4), 797-806. https://doi.org/10.1016/S0006-3495(90)82599-6

[5] Andreev, O. A., Karabadzhak, A. G., Weerakkody, D., Andreev, G. O., Engelman, D. M., \& Reshetnyak, Y. K. (2010). pH (low) insertion peptide (pHLIP) inserts across a lipid bilayer as a helix and exits by a different path. Proceedings of the National Academy of Sciences, 107(9), 4081-4086. https://doi.org/10.1073/pnas.0914330107

[6] Scott, H. L., Westerfield, J. M., \& Barrera, F. N. (2017). Determination of the Membrane Translocation pK of the pH-Low Insertion Peptide. Biophysical Journal, 113(4), 869-879. https://doi.org/10.1016/j.bpj.2017.06.065 